\title{
Skimming flow induced over a simulated polychaete tube lawn at low population densities
}

\author{
Michael Friedrichs*, Gerhard Graf, Barbara Springer \\ University of Rostock, Marine Biology Section, Freiligrathstrasse 7-8, 18055 Rostock, Germany
}

\begin{abstract}
Polychaete tube lawns with high population densities are frequent in marine soft-bottom environments. The influence of single tubes on near-bed flow dynamics has been quite well studied, but the critical population density that separates sediment destabilising effects from stabilising effects remains uncertain. This article presents results obtained with artificial tubes in a recirculating flume at a current velocity of $5 \mathrm{~cm} \mathrm{~s}^{-1}$. Four population densities were tested for their passive effects on the flow dynamics: expressed as percentage of the total surface area covered by tubes, they were 1.1, 2.0, 4.5 and $8.8 \%$. Using a high-resolution 3-dimensional current sensor, horizontal and vertical flow velocity profiles were recorded within the artificial tube lawns. An important deceleration of the current velocity was observed at all population densities, ranging from $38.2 \%$ at the lowest population density to $83.8 \%$ at the highest. This deceleration, the shape of the vertical profiles, the calculated Reynolds stress values and the direct observation of sediment displacement led to the conclusion that the flow field is modified to gradually raise the effective level of the bottom towards the tube tips, resulting in skimming flow conditions at $8.8 \%$ surface coverage. Compared with field conditions, this is still a relatively low population density and thus means that many natural tube lawns have sediment stabilising effects, conditioning the substratum for further benthic succession.
\end{abstract}

KEY WORDS: Polychaete tubes · Population density $\cdot$ Roughness density $\cdot$ Skimming flow $\cdot$ Flume Sediment erosion - Sediment stability

\section{INTRODUCTION}

The surface structure of soft-bottom marine environments is highly influenced by biogenic structures, such as mounds, pits, tracks, housings or excretory products. These can extend from a few millimetres to several centimetres into the water. The tubes of sessile polychaetes in particular may act as isolated obstructions in the current. However, tubes can also form dense lawns with high population densities (Fauchald \& Jumars 1979). Being immobile species, they rely on food particles drifting past them when filter feeding and depend on the deposition of these particles when deposit feeding. As even slow nearbed current velocities significantly exceed usual particle sinking rates, the main food source is the lateral particle flux (Jumars et al. 1981, Frithsen \& Doering

•E-mail: michael.friedrichs@biologie.uni-rostock.de
1986, Muschenheim 1987a, Rowe et al. 1994, Hawley \& Lesht 1995).

Active particle capture by polychaetes has been thoroughly described in the literature (Hempel 1957, Dorsett 1961, Dauer et al. 1981, Frithsen \& Doering 1986), but the passive effects of a tube lawn on the flow field and the surrounding sediment is still under discussion. Namely, the questions concerning sediment stabilising or destabilising not only remain unanswered (Graf \& Rosenberg 1997) but are discussed with contradictory conclusions. Some studies reveal a destabilising effect of tubes (Eckman et al. 1981, Luckenbach 1986), while others find highly stabilising effects, depending on the experimental set-up or on the choice of species (Daro \& Polk 1973, Rhoads et al. 1978, Frithsen \& Doering 1986). Even though the interaction of fluid, tubes and substratum was identified as a complex process long ago (Carey 1983), the information gathered since then has been incomplete. Single tubes have been shown to be surrounded by a vortex 
area that causes erosion, followed by deposition in the wake zone (Eckman \& Nowell 1984), but dense arrays of tubes are widely assumed to cause bed stabilisation (Carey 1983).

The population density at which sediment erosion effects of the tubes are replaced by stabilising flow dynamics still needs to be addressed. Nowell \& Church (1979) provided first results with small plastic bricks, showing a shift of the effective level of the sediment surface to the top of these elements (zero plane shift) when $1 / 12$ to $1 / 8$ of the total surface was covered, i.e. the logarithmic decrease of flow velocity within the bottom boundary layer reaches zero well above the sediment surface due to flow deflection and turbulent energy dissipation in the surroundings of these elements. The authors used 'roughness density' (RD), defined as the ratio of planar area of the roughness elements to total bed area, a dimensionless unit used to describe abundances of elements on a surface. While they focused their attention on gravel-type roughness in open channels, the present study deals with the passive influence of polychaete tubes, acting as biological roughness elements, on the flow over a marine soft-bottom sediment surface.

In the present study, the question of the influence of increasing roughness densities (i.e. population densities) on both the flow dynamics and the sediment stability in the surroundings of tube-shaped roughness elements is addressed by using direct observation of sediment movement and high-resolution flow velocity measurements.

\section{MATERIALS AND METHODS}

In a set of defined flume experiments the effects of artificial tube densities on the surrounding sediment were simulated for a pre-set flow field. These experiments were carried out in a recirculating flume at the GEOMAR laboratories (Research Centre for Marine Geosciences, Kiel, Germany). The flume design and instrumentation is described in detail in Springer et al. (1999). It is a recirculating seawater flume with a working channel of $3 \mathrm{~m}$ length and $40 \mathrm{~cm}$ width (Fig. 1). A test section is situated in the downstream part of the channel. It has a changeable bottom plate system of $105 \mathrm{~cm}$ length and $30 \mathrm{~cm}$ width. For experiments with salt water in natural sediments, original cores (e.g. from a multiple corer) can be introduced from below and adjusted to produce a surface flush with the surrounding sediment (usually the same sediment type without animals). The water level was $20 \mathrm{~cm}$ with a corresponding volume of $360 \mathrm{l}$. The return pipe contains a cooling system for experiments at controlled temperatures and a propeller that is connected to an adjustable electrical motor to generate the flow. Honeycomb collimators break up large-scale turbulent structures in the flow. An automated sensor-positioning system is mounted on top of the flume channel. It is made of a 3-dimensional mechanical moving unit, driven by stepping motors. Each axis is equipped with a stepping motor with a spatial resolution of $0.21 \mathrm{~mm}$, operated via a CNC-controller and an adapter and controlled by a PC.

Experimental set-up. The experimental layout consisted of solid PVC sticks with a constant height and diameter, simulating tubes of large polychaete species, e.g. Melinna cristata (Buchanan 1963, Fauchald \& Jumars 1979). The artificial tubes were $5 \mathrm{~cm}$ long and $0.54 \mathrm{~cm}$ in diameter (Table 1) and protruded $3.5 \mathrm{~cm}$ above the sand surface. They were arranged in holes on an $18 \mathrm{~cm}$ by $28 \mathrm{~cm}$ PVC baseboard, following a regular pattern. This regular pattern is more likely to

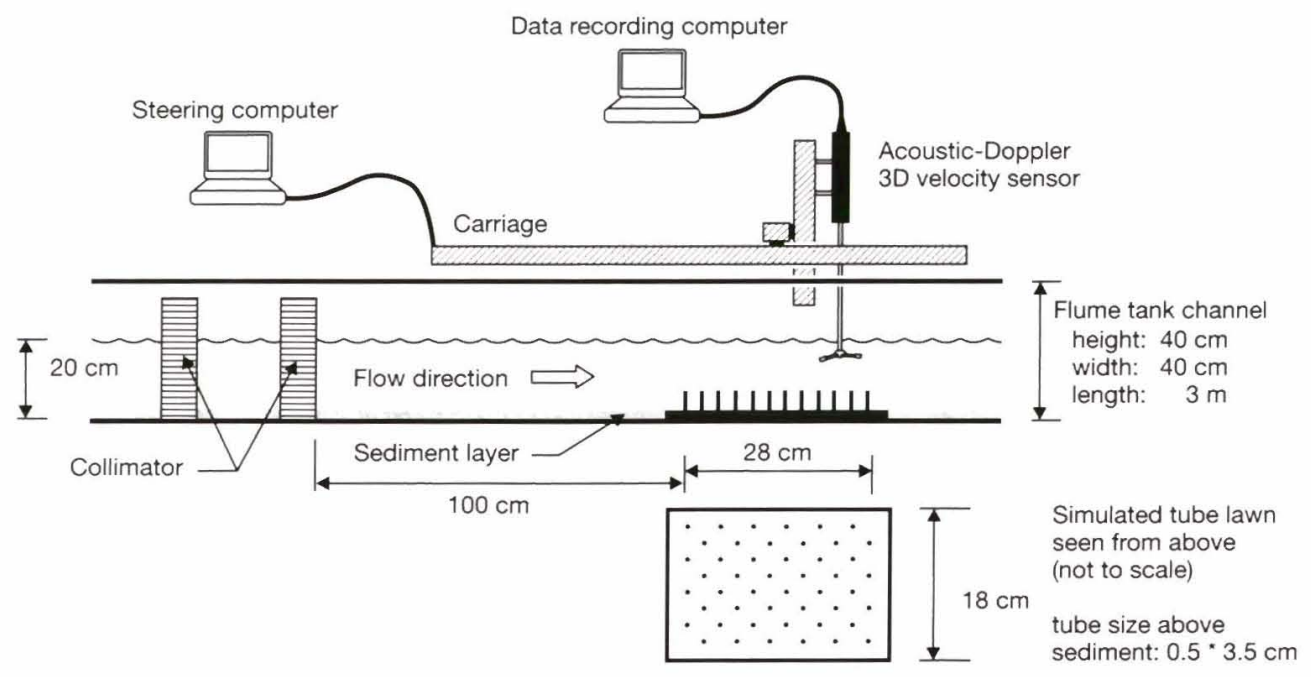

Fig. 1. Schematic of the experimental set-up in the flume channel. Flow direction is left to right. Inlet and outlet of the return pipe are not shown. Water level was $20 \mathrm{~cm}$ in the experiments. The artificial tube lawns were positioned in the test section, at $100 \mathrm{~cm}$ downstream from the collimators. The tube lawns were $28 \mathrm{~cm}$ long and $18 \mathrm{~cm}$ wide, their base plates being covered by a thin layer of sand. On top of the flume channel, a positioning carriage holds the acoustic Doppler flowvelocity sensor 
Table 1. Outline of the experimental set-up and of some important parameters characterising the flow conditions present in the flume during the control run (no tubes). Reynolds number, Reynolds stress and turbulence intensity are common ways to express the turbulence level. The Reynolds number gives a ratio of inertial to viscous forces, indicating the switch from laminar to transitional (values above 40) and to fully turbulent (above 200 000) conditions. Within the boundary layer, turbulent conditions occur at Reynolds number values above 3000 . Turbulence intensity is the ratio of standard deviation to mean flow velocity, expressed as a percentage. Values around $10 \%$ are usually found in the field

\begin{tabular}{|c|c|c|}
\hline \multicolumn{3}{|l|}{ Tubes } \\
\hline \multicolumn{2}{|c|}{ Height above sand surface } & $3.5 \mathrm{~cm}$ \\
\hline \multicolumn{2}{|l|}{ Diameter } & $0.5 \mathrm{~cm}$ \\
\hline \multicolumn{2}{|c|}{ Aspect ratio (height/diameter) } & 7 \\
\hline \multicolumn{3}{|l|}{ Lawns } \\
\hline \multicolumn{2}{|c|}{ Roughness density (RD) } & lance (no. $\mathrm{m}^{-2}$ ) \\
\hline $1 / 89.1$ & 0.011 & 490 \\
\hline $1 / 50.1$ & 0.020 & 872 \\
\hline $1 / 22.3$ & 0.045 & 1961 \\
\hline $1 / 11.4$ & 0.088 & 3836 \\
\hline \multicolumn{3}{|l|}{ Sand } \\
\hline \multicolumn{2}{|c|}{ Inorganic quartz mean grain size } & $400 \mu \mathrm{m}$ \\
\hline \multicolumn{3}{|l|}{ Flow } \\
\hline \multicolumn{2}{|l|}{ Depth } & $20 \mathrm{~cm}$ \\
\hline \multicolumn{2}{|l|}{ Velocity } & $5 \mathrm{~cm} \mathrm{~s}^{-1}$ \\
\hline \multicolumn{2}{|c|}{ Reynolds number ( $R e$ ) using flow depth } & 10000 \\
\hline \multicolumn{2}{|c|}{ Boundary layer thickness $(\delta)$} & $3 \mathrm{~cm}$ \\
\hline \multicolumn{2}{|c|}{ Boundary layer Reynolds number $\left(R e_{\delta}\right)$} & 1500 \\
\hline \multicolumn{2}{|c|}{ Reynolds stress } & $3 \times 10^{-3} \mathrm{~N} \mathrm{~m}^{-2}$ \\
\hline \multicolumn{2}{|c|}{ Turbulence intensity } & $11 \%$ \\
\hline \multicolumn{2}{|c|}{ Bottom shear velocity $(u)}$. & $0.3 \mathrm{~cm} \mathrm{~s}^{-1}$ \\
\hline \multicolumn{2}{|c|}{ Roughness length $\left(z_{0}\right)$ of sand used } & $300 \mu \mathrm{m}$ \\
\hline
\end{tabular}

give general trends than a patchy or random distribution. It was then placed into the test section of the flume (Fig. 1) and covered by a thin layer of noncohesive, inorganic quartz sand (mean grain size $400 \mu \mathrm{m}$ ) which masked the base plate. The lateral edges of the tube lawn were $11 \mathrm{~cm}$ away from the side walls of the flume channel. With a water level of $20 \mathrm{~cm}$ in the flume channel, the tube tips were submersed, leaving $15 \mathrm{~cm}$ of water above them. One control run without tubes and 4 different roughness densities (RDs), defined as the ratio of planar area of the roughness elements to total bed area, were tested for their effects on the flow dynamics. The 4 RDs were $0.011,0.020$, 0.045 and 0.088 , using commonly observed population densities for tubes of this size. As the artificial tube diameter was $0.54 \mathrm{~cm}$, these RDs corresponded to population densities of 490,872, 1961 and 3836 tubes $\mathrm{m}^{-2}$, respectively. In the literature, population densities reported e.g. for Melinna cristata range between 162 (Rosenberg 1976) and more than $5000 \mathrm{~m}^{-2}$ (Buchanan 1963).
Flow measurements. The sensor used to measure current velocities was a 3-dimensional acoustic Doppler velocimeter, ADV (SonTek, San Diego, USA). The flow velocity in the flume was set to a constant free-stream velocity value of $5 \mathrm{~cm} \mathrm{~s}^{-1}$ measured well above the boundary layer at $8 \mathrm{~cm}$ from the sediment surface. Studies in the Mecklenburg Bight, Baltic Sea, reported flow velocities between 2 and $6 \mathrm{~cm} \mathrm{~s}^{-1}$ at $1 \mathrm{~m}$ above the sea floor in shallow waters (Stips et al. 1998). Table 1 gives an overview of the hydrodynamic conditions generated within the test section of the flume. The flow sensor is drift-free and thus does not require routine recalibration. It gives a simultaneous record of the 3 spatial flow components $u, v$ and $w$ (streamwise direction, transversal and vertical component, respectively). The data recording rate was set to $15 \mathrm{~Hz}$. The sensor works with the acoustic Doppler method, emitting a sound beam that is reflected on a virtual measurement cell in the water at $5 \mathrm{~cm}$ below the sensor head. It thus operates on a nearly non-intrusive mode, enabling measurements of the flow even around the artificial tubes. A 3-dimensional positioning system (Fig. 1, cf. Springer et al. 1999) was used for measurements of both high-resolution vertical velocity profiles and planar 2-dimensional patterns, designated as horizontal profiles in this study. For the control run and each RD, both a vertical profile and a horizontal measurement were recorded. Replicates were not measured due to the large quantity of data obtained for each runwhich were averaged instead during data treatment, as described in 'Data treatment' below. The differences between replicates would have been filtered out during data treatment.

The vertical profiles were taken in the centre of the downstream half of the tube arrays. These profiles consisted of time-series of $30 \mathrm{~s}$ each, taken with a vertical spacing of $1 \mathrm{~mm}$ within the lowest $5 \mathrm{~cm}$ and $2 \mathrm{~mm}$ in the upper part.

The planar measurements covered an area of $10 \mathrm{~cm}$ by $30 \mathrm{~cm}$ through the centre of the $18 \mathrm{~cm}$ by $28 \mathrm{~cm}$ tube arrays, recording the full extent of the set-up along the streamwise axis but leaving margins of $4 \mathrm{~cm}$ from each lateral edge of the tube lawn to ensure that lateral flow effects did not alter the results. These measurements were performed at a height of $1.5 \mathrm{~cm}$ above the sediment, with a spatial resolution in steps of $5 \mathrm{~mm}$ (1365 single points). The positioning carriage remained at each of these points for $5 \mathrm{~s}$, recording continuously.

All experiments were carried out at ambient temperature (about $20^{\circ} \mathrm{C}$ ) using fresh water with an enhanced particle load (SonTek glass bead seeding material) to provide a good scattering level for the ADV flow sensor.

Data treatment. For the horizontal profiles, extraction software was used to allocate the recorded flow 
velocities to the respective positions within the tube array and to calculate the mean value and standard deviation for each flow component at each of these positions. To assess the flow deceleration when passing the tube array, an average flow velocity was then calculated from the horizontal profile results at 5 positions along the streamwise axis: $2 \mathrm{~cm}$ upstream from the tube array leading edge, 8,15 and $22 \mathrm{~cm}$ downstream from it, and at the downstream end of the array. At each of these 5 positions, mean flow velocity and its standard deviation were determined from a transversal (cross-flow) section that covered 63 single measurement points. For the vertical profiles, mean flow velocity and its standard deviation were calculated from the $30 \mathrm{~s}$ time-series measured at each height.

A common parameter describing turbulent flow conditions is turbulent, or Reynolds, stress (Gust 1989, Butman et al. 1994, Lohrmann et al. 1995). A measured instantaneous horizontal flow velocity $u$ can be separated into a mean flow velocity $\bar{u}$ and a fluctuating part $u^{\prime}$ that contains turbulent energy $\left(u^{\prime}=u-\bar{u}\right)$. Similarly, the transversal and vertical flow component fluctuations are $v^{\prime}$ and $w^{\prime}$. By definition, the negative Reynolds stress is obtained from a measured flow velocity time series by multiplying water density $(\rho)$ with the average of the products of the fluctuations of 2 flow components: $\rho \overline{u^{\prime} v^{\prime}}, \rho \overline{u^{\prime} w^{\prime}}$ and $\rho \overline{v^{\prime} w^{\prime}}\left(\mathrm{g} \mathrm{cm}^{-1} \mathrm{~s}^{-2}\right.$, or in pressure units: $10^{-1} \mathrm{~N} \mathrm{~m}^{-2}$ ). Each of these values gives the intensity of turbulent fluctuations along a 2-dimensional plane: streamwise-transversal, streamwisevertical and transversal-vertical, respectively. In the present study, stress values were calculated from the time-series measured in the vertical velocity profiles. These 3 stress values were then added to form a 'total stress' term.

The plots of vertical profiles were smoothed by means of 5-point adjacent averaging to emphasise the trends. The plots of horizontal profiles were matrix-smoothed by unweighted averaging. To facilitate the comparison of results, measured flow velocities were transformed into percentage values. A reference height and position was therefore fixed to obtain a $100 \%$ value. This reference point was chosen once for the vertical profiles and once for the horizontal measurements. It was outside the boundary layer at $8 \mathrm{~cm}$ above the sediment surface for the vertical velocity profiles, while the horizontal measurements were referenced to a point situated at $1.5 \mathrm{~cm}$ height and $2 \mathrm{~cm}$ upstream from the leading edge of the tube lawns, where flow was unaffected by the tubes.

Photographic records. In addition to the flow measurements, sediment displacement in the tube arrays was observed directly. Following the completion of the flow measurements, flow velocity was increased to $20 \mathrm{~cm} \mathrm{~s}^{-1}$, a subcritical erosion flow velocity of the non-cohesive sand grains used here. It directly generated neither erosion nor bedload transport in the control experiment with a smooth and bare sediment surface. In contrast, the high vorticity that develops in the presence of tubes initiates movement of the sediment (Carey 1983, Eckman \& Nowell 1984). For documentation, a photograph of the sediment surface inside the tube array was taken after $1 \mathrm{~h}$ at $20 \mathrm{~cm} \mathrm{~s}^{-1}$ for each RD tested. This set-up was chosen as a test for the flow measurements, allowing the recorded data to be checked with actual sediment effects. The increased flow velocity was necessary to initiate sediment movement but lies beyond the range of optimum velocities for high-quality flow measurements in the flume used here. The measurements of flow-velocity profiles were thus not repeated in this experiment.

\section{RESULTS}

Horizontal measurements at $1.5 \mathrm{~cm}$ height showed a decrease of flow velocity with distance from the leading edge of the tube array caused by different RDs (Fig. 2). Apart from the control run, 2 groups formed gradually. Considering values at the downstream end of the tube arrays, flow deceleration at RDs of 0.011 and 0.020 form a statistically homogenous group, as do the 0.045 and 0.088 arrays (Table 2). These 2 groups differ significantly from each other (Tukey test; $\mathrm{p}<0.05$ ) and from the control experiment. The steepest gradient was located within the first $8 \mathrm{~cm}$ downstream from the leading edge; the slope flattened until asymptoti-

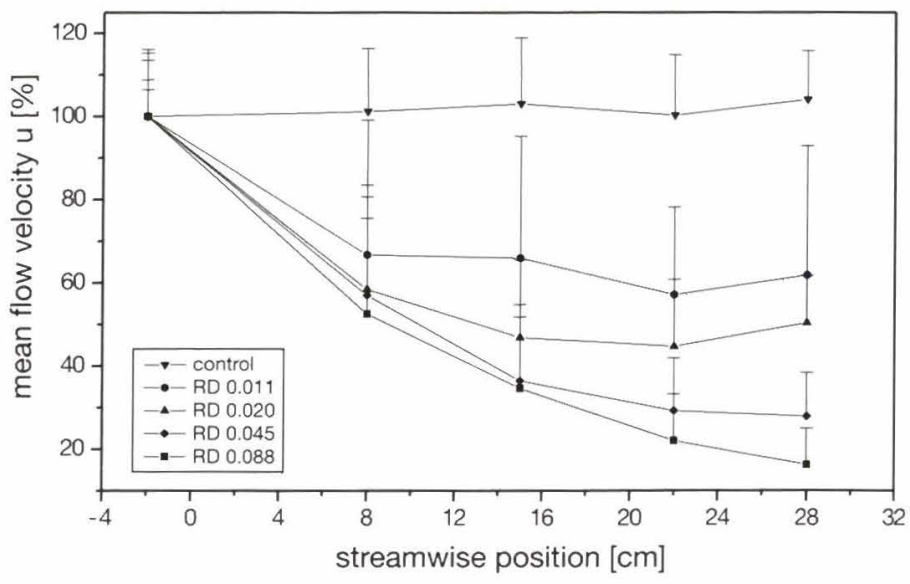

Fig. 2. Flow deceleration at different roughness densities (RDs) shown as a function of distance downstream from the leading edge of the tube lawn (main flow component $u$ in percent of reference velocity at $1.5 \mathrm{~cm}$ above sediment surface). Error bars indicate the standard deviation $(n=63)$ and are only shown in 1 direction to reduce overlap 
Table 2. Results overview. The main flow component $(u)$ at $1.5 \mathrm{~cm}$ above the sediment surface as a percentage of the reference value is given. The results measured in the horizontal profiles at the downstream end of the tube arrays are listed, as are the results from the vertical profiles. Height and value of the stress peak are taken from data of the vertical stress profiles

\begin{tabular}{|lrrrr|}
\hline $\begin{array}{l}\text { Roughness } \\
\text { density, RD }\end{array}$ & $\begin{array}{r}\text { Mean flow velocity, } u(\%) \\
\text { Horizontal profiles }\end{array}$ & $\begin{array}{c}\text { Peak height } \\
(\mathrm{cm})\end{array}$ & $\begin{array}{c}\text { Peak value } \\
\left(10^{-3} \mathrm{~N} \mathrm{~m}^{-2}\right)\end{array}$ \\
\hline 0.000 & 104.0 & 100.0 & 0.6 & 6 \\
0.011 & 61.8 & 70.8 & 1.2 & 15 \\
0.020 & 50.3 & 41.1 & 1.6 & 19 \\
0.045 & 27.8 & 30.1 & 3.7 & 18 \\
0.088 & 16.2 & 16.5 & 5.2 & 13 \\
\hline
\end{tabular}

the results were difficult to compare. The vertical profiles were measured farther upstream, well within the tube lawns at $25 \mathrm{~cm}$ from their leading edge, and the mean deceleration was averaged over heights of 1 to $2 \mathrm{~cm}$, including about 10 results. From the horizontal profiles, mean deceleration was obtained at the downstream end of the tube lawns and was averaged over 63 single results, all taken at the same height. Therefore, these deceleration results differ between the 2 experiments, especially at the lowest RD of 0.011 .

cally reaching steady-state values farther downstream. An additional test run (not shown here) in which the complete test section was covered by artificial tubes at an $\mathrm{RD}$ of 0.020 revealed that no further changes of the flow conditions occurred within the lawn beyond a distance of $20 \mathrm{~cm}$ downstream from its leading edge. The value of $104 \%$ in the control experiment could possibly be due to shear stress imposed in the upper water column, depending on flow speed and flume design.

At the lowest RD (0.011, Fig. 3a), horizontal measurements showed only a gradual overall decrease of flow velocity throughout the tube field. At the downstream end of this array, the flow was still at $61.8 \%$ of its original strength. However, a field of reduced flow formed around each tube, but these wakes hardly touched each other. With increasing RD, the level of interaction between these tube-adherent flow fields increased gradually. At RD 0.020 (Fig. 3b), these fields were still surrounding each tube but were partially connected. The overall flow decrease remained moderate, the flow being $50.3 \%$ of its original strength at the downstream end of the array. In contrast, the flow velocity was slowed down considerably when passing through the tube array at RDs of 0.045 (27.8\%) and $0.088(16.2 \%)$. The isolines of constant flow velocity no longer marked circles around each single tube, but depicted a clear streamwise gradient (Fig. 3c,d).

A well-developed boundary layer was present in the control situation of the vertical current profiles (Fig. 4). With increasing RD, boundary layer formation was disturbed at the bed level. Close to the bed, at a height of $1.5 \mathrm{~cm}$ (averaged over data from heights of 1 to $2 \mathrm{~cm}$ ), the relative flow velocity decreased gradually with an increasing number of tubes to $70.8,41.1,30.1$ and $16.5 \%$, respectively. The zero level of the boundary layer was gradually shifted towards the height of the tube tips until reaching it at $\mathrm{RD} 0.088$. The respective heights were $0.003 \mathrm{~cm}$ in the control run and $0.07,0.7,2.0$ and $3.3 \mathrm{~cm}$ for the different RDs. Although the height of $1.5 \mathrm{~cm}$ was chosen in the vertical profiles to check for flow deceleration at the same height as that in the horizontal profiles,
In the vertical profiles of Reynolds stress (Fig. 5), the control showed an increased stress level close to the sediment due to the high gradients in the lowest part of the bottom boundary layer. In the measurements with tube arrays, a clear stress peak was visible, indicating increased turbulence. At a low RD, this turbulence peak was close to the sediment surface, but gradually shifted to the level of the tube tips (Table 2). It reached the tube tip height at RD 0.045 and was beyond it at RD 0.088. The highest stress values occurred at the intermediate RDs of 0.020 and 0.045 , while the maximum value was lower at RD 0.011 and 0.088. Stress was generally low in the upper part of all the profiles, well above the tubes.

Sand movement observed at $20 \mathrm{~cm} \mathrm{~s}^{-1}$ agreed with the horizontal current profiles. The smooth sediment surface of the control experiment remained unchanged. In contrast, typical horseshoe-shaped pits surrounded the base of the tubes throughout the entire array at the lower RDs. Fig. 6 shows a side view (Fig. 6a) and top view (Fig. 6b) of the RD 0.011 set-up. The eroded sediment was partly redeposited in a mound on the downstream part of the tubes. A similar observation was made at RD 0.020 (not shown). At the higher RDs of 0.045 (Fig. 6c) and 0.088 (not shown), only the upstream half of the tube fields was affected by sediment displacement. It was less pronounced than at RD 0.011, but still present. The pits were smaller and the mounds shorter, a consequence of the narrower spacing of the tubes. The downstream half of the tube-covered area remained unchanged. Only the lateral edges of this area were still influenced by the flow and showed partial sediment erosion.

\section{DISCUSSION}

According to Nowell \& Jumars (1987), flume experiments require dynamic similarity to field conditions and thus adequate scaling. As an additional rule, objects should not exceed $35 \%$ of the total flow depth 
a)

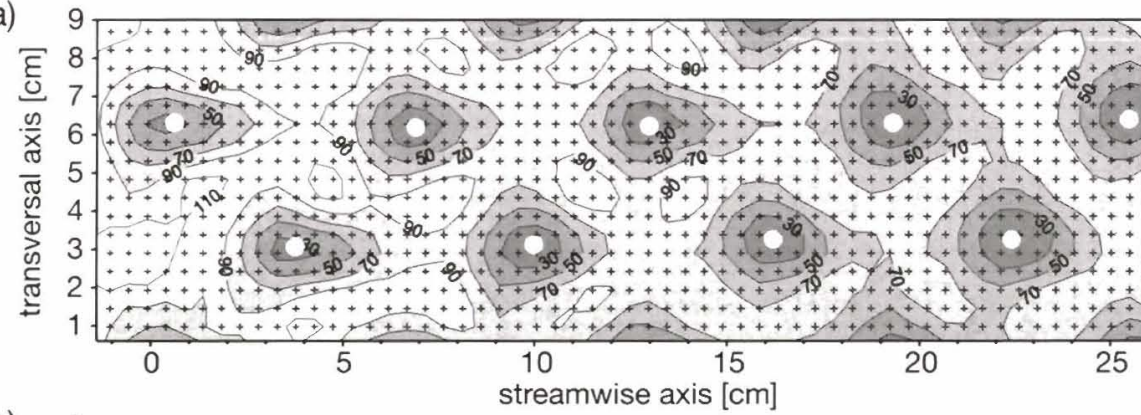

b)

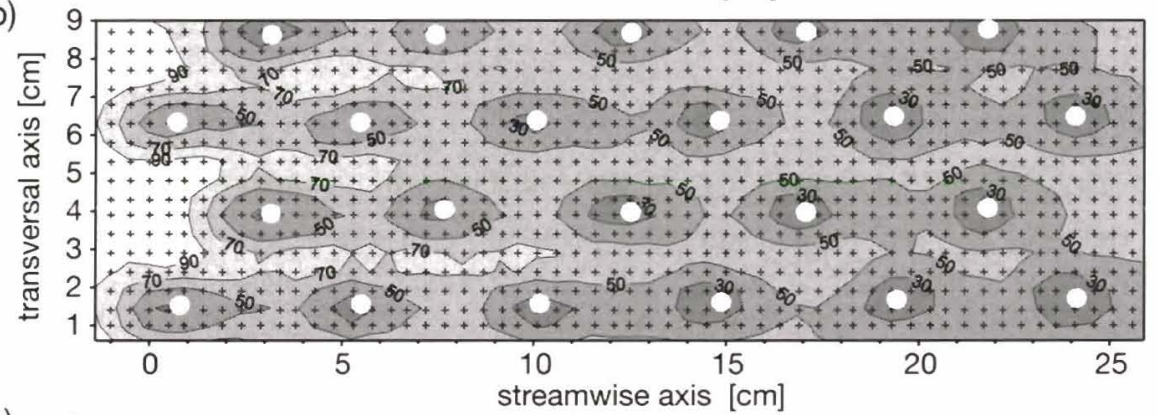

c)

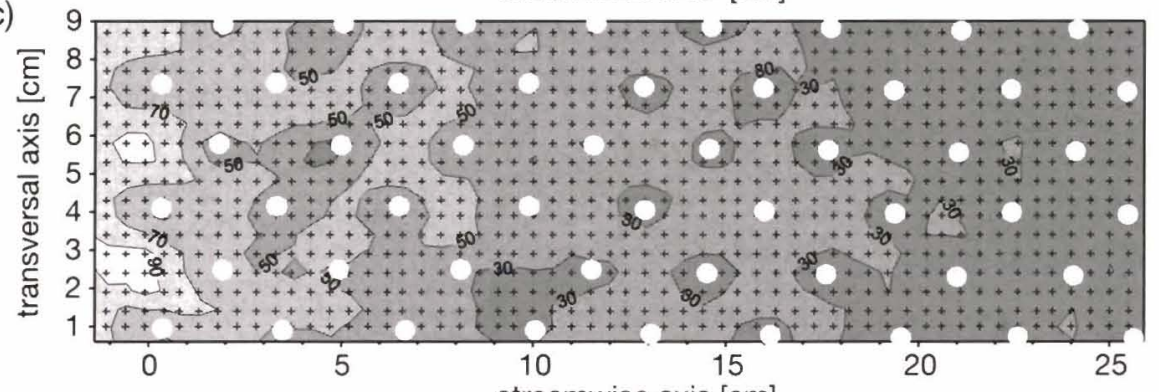

d)

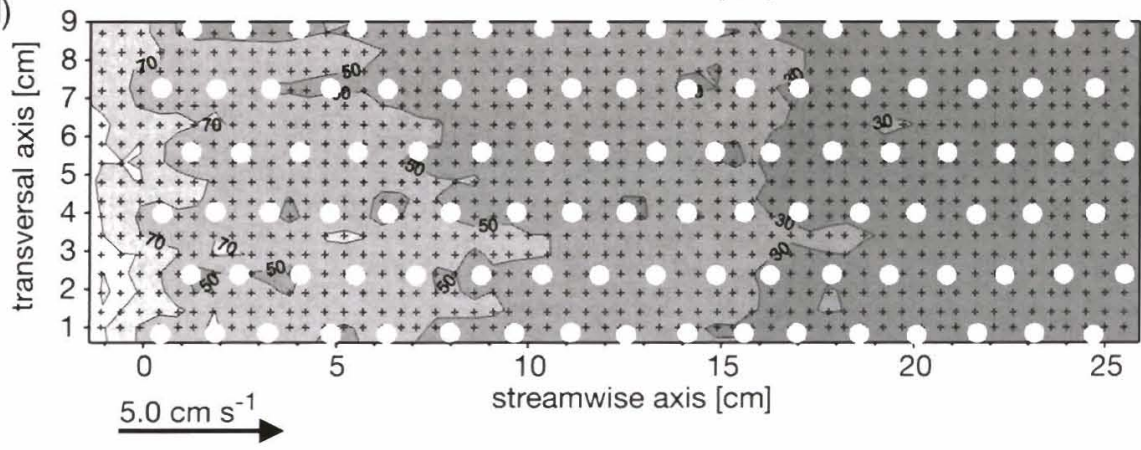

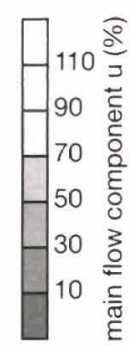

Fig. 3. Current velocity field in presence of artificial tubes at an RD of (a) 0.011, (b) 0.020, (c) 0.045 and (d) 0.088 . Flow values are expressed as a percentage of the reference velocity at $1.5 \mathrm{~cm}$ above sediment surface (main flow component $u$ in $\%$, matrix averaged). (O) Tube positions. (+) Points of current measurements. Flow direction was left to right, as indicated by the arrow to avoid a blocking of the flow. In this study, the size of the artificial tubes did not exceed one-third of the flow depth, but did not reflect field conditions with respect to boundary layer height. In coastal and shallow waters, bottom boundary layer heights are found from 10 to $60 \mathrm{~cm}$ (Ackerman 1986) up to $5 \mathrm{~m}$ (Gust 1989), depending on flow conditions and bottom characteristics. The boundary layer in the flume used here only extended to a height of about $3 \mathrm{~cm}$, while the artificial tubes protruded $3.5 \mathrm{~cm}$ from the sediment surface. The horizontal measurements at $1.5 \mathrm{~cm}$ height were still within the boundary layer, but the vertical profiles may have been influenced by the fact that the boundary layer was shallow. Nevertheless, as the vertical profiles were taken deep inside the tube arrays, the original boundary layer was already highly disturbed by the tubes further upstream from the measurement position. Results may therefore vary with different experimental settings but the observations made in the near-bed region are likely to be qualitatively correct. The flow deceleration observed in a larger flume at NIOO-CEMO, Yerseke, The Netherlands (Friedrichs 1997), with a boundary layer height of $20 \mathrm{~cm}$ did not differ significantly from the results presented in this 
main flow component $\mathrm{u}\left[\mathrm{cm} \mathrm{s}^{-1}\right]$
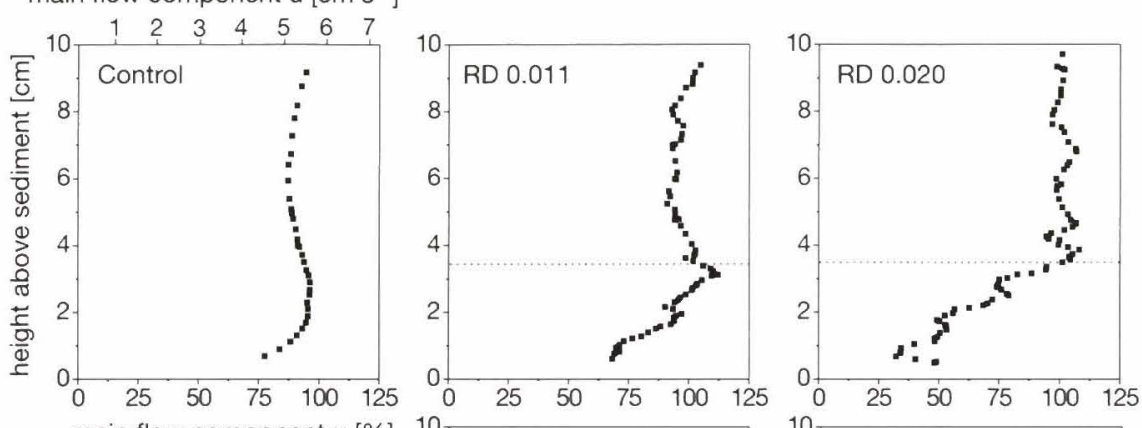

main flow component $u[\%]$
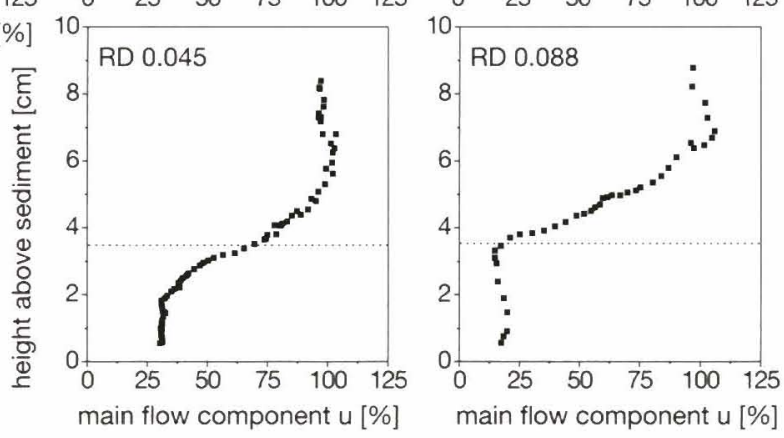

Fig. 4. Vertical profiles of current velocity $u$ (main flow component $u$ as a percentage of the reference velocity at $8 \mathrm{~cm}$ above sediment surface) taken in the downstream half of the artificial tube lawns at different RDs. (…) Height of the tube tips. The data shown are smoothed by adjacent averaging over 5 points
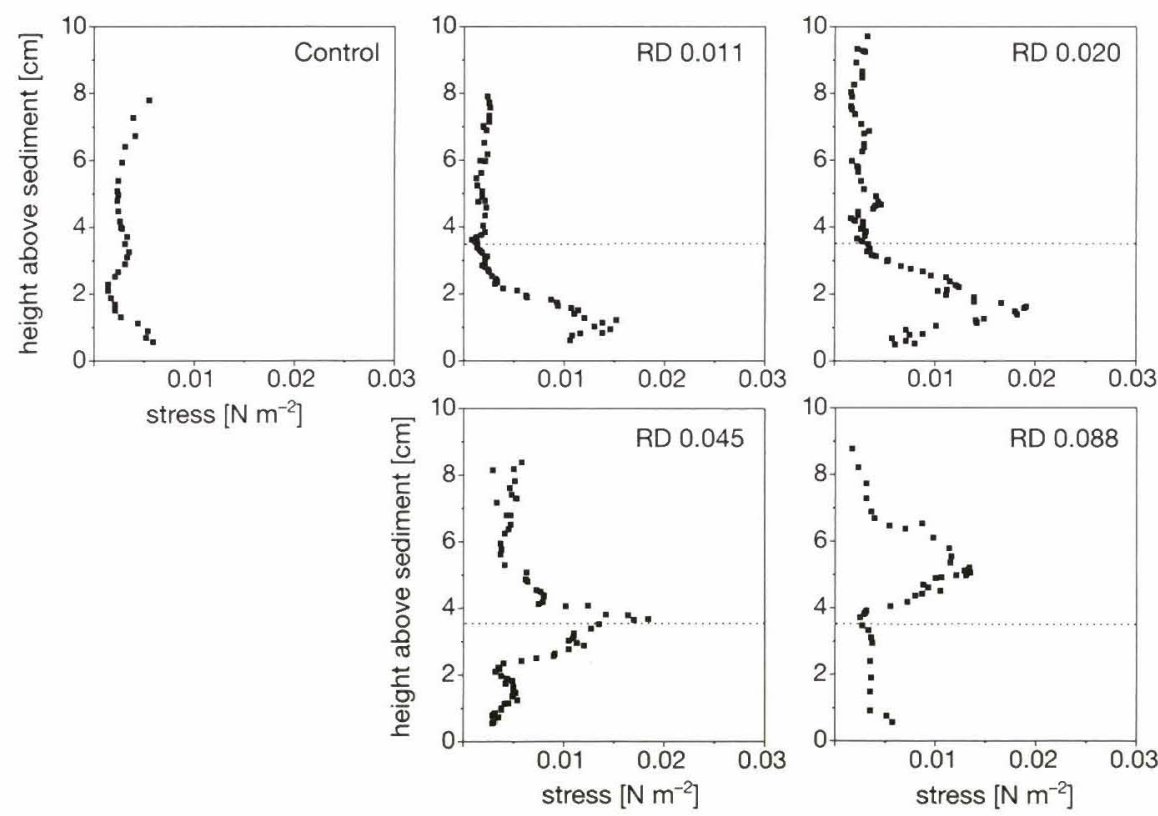

Fig. 5. Vertical profiles of total Reynolds stress taken in the downstream half of the different artificial tube lawns. (....) Height of the tube tips. The data shown are smoothed by adjacent averaging over 5 points

study. Although a proper scaling would have been valuable, this study nevertheless presents results obtained under flow conditions that were kept constant in each experiment run. The trends discussed in the following thus reflect effects observed under repeatable and comparable conditions.

The data presented here are based on idealised tube lawns with regular spacing, while natural polychaete populations are merely found in patches and with variable tube heights. This means that densely populated spots alter with bare sediment surfaces. Hence, the effects of tube lawns could be more restricted to smaller areas and alternate between local scour and deposition, especially under oscillating tidal-current conditions.

Three flow conditions have been described for a near-bed current over a rough bottom (Vogel 1994). An 'independent flow' is characterised by roughness elements with a much smaller height than the distance between them, where each element acts essentially alone in the flow. These elements form a vortex both upstream and downstream of their body. There is no wake interaction between neighbouring elements. The 'interactive flow' occurs when elements only have a spacing moderately greater than their height and where vortex patterns downstream from one element start interacting with the vortex upstream from the following element. A 'skimming flow' is given when the roughness element spacing is equal to or less than the element height and it raises the effective level of the bottom surface.

In the present study, 2 of these conditions were observed. Two groups can be formed, separating the results of RDs 0.011 and 0.020 from those of RDs 0.045 and 0.088 . In the first group, isolated wake fields and sporadic interaction were observed in the horizontal profiles (Fig. 3). Current velocity was decelerated by less than $50 \%$ at the downstream end of the tube array. In the vertical current profiles, the zero plane shift was only 1.0 and $1.7 \mathrm{~cm}$, respectively, for RDs 0.011 and 0.020 . The Reynolds stress profile also showed a peak well below the height of the tube tips. In contrast, the second group had a high degree of wake interaction. Flow velocity was reduced by more than two-thirds 

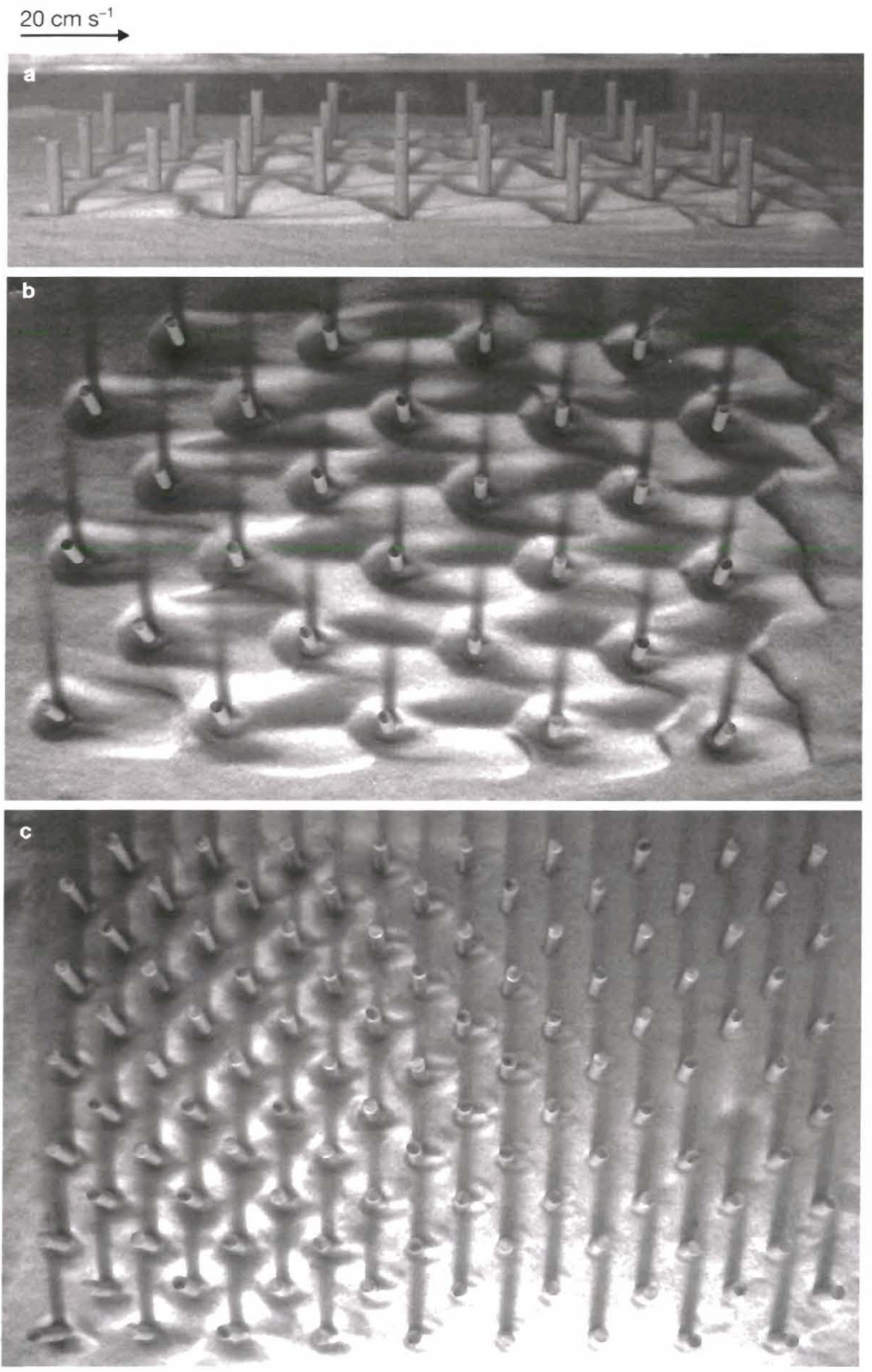

Fig. 6. Sediment movements generated in the flume at $20 \mathrm{~cm} \mathrm{~s}^{-1}$ flow velocity. (a) Side view and (b) top view of an array with $\mathrm{RD}=0.011$ showing significant sediment transport throughout the tube area. Typical horseshoe-shaped pits surround the tubes, with redeposited sand mounds in the tube wake areas. (c) Top view at $\mathrm{RD}=0.045$; the upstream part of the tube area is less affected and the downstream part is unchanged. The black arrow marks the flow direction

and the zero plane shift of the vertical velocity profiles was 2.6 and $3.3 \mathrm{~cm}$, respectively, for RDs 0.045 and 0.088 . Maximum values of tube-generated stress were reached in the specific boundary layer conditions above the tube field at heights of 3.7 and $5.2 \mathrm{~cm}$, which are above the tube tips. However, a closer look at the Reynolds stress profiles suggests a different grouping due to the stress level and the height of the stress peak (Table 2). With a low Reynolds stress and a stress peak near the sediment for RD 0.011 , this situation was still close to the control conditions. At RDs 0.020 and 0.045 , higher stress values indicated the presence of turbulence at intermediate heights between the tubes. In the last set-up with RD 0.088, the stress peak shifted above the tube tips and was lower than in RDs 0.020 and 0.045 due to a decreased turbulence level between the tubes. Although the differences in stress peak values were not significant, these observations led to a description of the flow as interactive for RDs $0.011,0.020$ and 0.045 while it was skimming for RD 0.088 .

Observations of sediment displacement within the tube arrays at a higher current velocity indicated erosion occurring throughout the tube arrays at low population densities up to an RD of 0.020 . This means that under the conditions tested here, the sediment was only destabilised until $2 \%$ of the sediment surface was covered by tubes. The corresponding population density in the field is about 872 tubes $\mathrm{m}^{-2}$. At higher densities, only the tubes in the close vicinity of the leading edge induced erosion. The flow was strongly decelerated and hence the residence time of particles within the tube array increased. These conditions are likely to facilitate deposition. Such a tube lawn will both enhance the resuspension of sediment material in its outer regions (Fig. 6c) and cause deposition of particles in its centre. For densely populated tube fields, Daro \& Polk (1973) reported a rise of the sediment surface by up to $50 \mathrm{~cm}$ due to increased accumulation and capture by Polydora ciliata, a small spionid polychaete found in patches of more than $10^{6}$ tubes $\mathrm{m}^{-2}$. Assuming a tube diameter of $1 \mathrm{~mm}, 10^{6}$ tubes $\mathrm{m}^{-2}$ of $P$. ciliata correspond to an RD of 0.80 . Other polychaete species also occur at high population densities: Spio setosa was found at densities of up to $2000 \mathrm{~m}^{-2}$ by Muschenheim (1987b) and Melinna cristata occurred at densities of as high as $5000 \mathrm{~m}^{-2}$ (Buchanan 1963). The corresponding RD values are 0.04 for $S$. setosa and 0.10 for $M$. cristata.

In conclusion, the sediment movement observations reveal a clear shift from destabilising effects to stabilising effects of the tubes between RD values of 0.020 and 0.045 . The flow measurements indicate the occurrence of skimming flow at RD 0.045 or RD 0.088 , depending 
on the importance attached to either the flow velocity or stress results. When compared with population densities reported in the literature, this creates a high probability for passive bed stabilisation within many of the commonly observed tube lawns in the field, but additional tests are necessary to reveal how far these flume results will be applicable to field conditions.

These findings can, however, be slightly different with a natural, i.e. patchy or random, distribution of tubes. It may also be important to have a closer look at the role of tube flexibility in future studies. While some species have rather rigid tubes, e.g. Melinna cristata (Fauchald \& Jumars 1979), Lanice conchilega (Carey 1983) or Spio setosa (Muschenheim 1987b), other tubes are flexible and bend with the current, such as Polydora ciliata (Hempel 1957, Dorsett 1961). It is then conceivable that such tubes induce the creation of a canopy layer comparable to those observed in the presence of seagrass (Gambi et al. 1990). Another study (Eckman et al. 1981) emphasises the creation of pits around tubes of Owenia fusiformis, partly due to its flexibility in the flow and partly maintained by active sweeping of the tube, enhancing the trapping of bedload material.

Such passive effects on sediment stability are only one of the consequences of the presence of tubes. Another consequence of much greater significance for the polychaete itself is the resulting change in food availability and the necessity to adapt feeding strategies. Tube-building, sessile polychaetes depend on the combined effects of their active and passive particle capture mechanisms for food supply. In addition to their feeding behaviour, polychaetes can benefit from the presence of their tube to enhance the efficiency and quality of the captured matter.

At low population densities, each tube is isolated. The polychaete thus has to ensure its own food supply. Carey (1983) observed pathlines of food particles around single polychaete tubes, demonstrating the advantage of local resuspension and particle retention in the wake area of the tentacle fringe of Lanice conchilega. In a different approach, Muschenheim (1987b) described the importance of hydrodynamic sorting of seston and the advantage of tube-building for Spio setosa. Worms with tubes shortened to bed level ingested seston of significantly lower organic quality than worms feeding in intact tubes at 4 to $6 \mathrm{~cm}$ above the bed, both still having a better diet quality than the composition of the ambient sediment surface. Both authors presented results that underline the advantage of tube-building for suspension-feeding polychaetes under independent or interactive flow conditions, in other words at low population densities.

At higher population densities, which are only sustainable under a favourable supply of food, the nearbed current turns into skimming flow. As shown in the sand erosion experiment, the upstream edge of a tube lawn will still be subject to scouring. The sharp gradient of flow velocity when entering the tube field offers enhanced particle capture conditions. The current velocity is strongly reduced, while the sinking rate of particles remains unchanged, ranging from around $10^{-5}$ to $10^{-1} \mathrm{~cm} \mathrm{~s}^{-1}$, as summarised by Shimeta \& Jumars (1991). These particles are retained and eventually deposited around the tubes. The efficiency of this particle trapping depends on the streamwise length of the tube field and on flow velocity. Under unidirectional and constant flow conditions, the combined effect of a slow flow velocity and of the size of the tube field can lead to food depletion, even in the presence of high seston concentrations. This phenomenon is well documented for bivalve beds (O'Riordan et al. 1993, Butman et al. 1994). In contrast, an oscillating flow, which means regularly reversed flow directions, would result in a high retention rate. Here, the changing flow direction leads to food supply to the tube lawn from different sides, including stagnant water during flow direction changes.

Particle trapping capacity may be of major importance in the recolonisation of disturbed or defaunated substrates. Many spionids are fast-growing opportunistic species with a high potential for mass development (Dauer et al. 1981, Noji \& Noji 1991). Being interface feeders, they are able to switch from suspension to deposit feeding and thus also benefit from particle accumulation in dense tube arrays. Taghon et al. (1980) documented a behaviour shift from deposit feeding to suspension feeding for different spionid species at current velocities between 2 and $5 \mathrm{~cm} \mathrm{~s}^{-1}$. Miller et al. (1992) tested this switch for Spio setosa in an oscillatory flow and found an optimum flow velocity of $6.5 \mathrm{~cm} \mathrm{~s}^{-1}$ for suspension feeding. With this adaptable feeding behaviour, a good utilisation of available food resources is possible. A dense population will then help to stabilise disturbed sediment surfaces and condition the bed for future recolonisation by macrofauna species. The spionids are gradually replaced during succession of the benthic community (Rosenberg 1976, Noji \& Noji 1991).

Acknowledgements. We gratefully appreciate the assistance of L. Thomsen, W. Ritzrau and U. Witte at GEOMAR in Kiel and of S. Forster at IOW in Rostock for their critical comments on earlier versions of the manuscript. Thanks are due to $\mathrm{W}$. Queisser, A. Cremer and J. Nittikowski for their valuable technical knowledge. We also thank 4 anonymous reviewers for their helpful comments on the manuscript.

\section{LITERATURE CITED}

Ackerman JD (1986) Mechanistic implications for pollination in the marine angiosperm Zostera marina. Aquat Bot 24: 343-353 
Buchanan JB (1963) The bottom fauna communities and their sediment relationships off the coast of Northumberland Oikos 14:154-175

Butman CA, Fréchette M, Geyer WR, Starczak VR (1994) Flume experiments on food supply to the blue mussel Mytilus edulis L. as a function of boundary-layer flow. Limnol Oceanogr 39:1755-1768

Carey DA (1983) Particle resuspension in the benthic boundary layer induced by flow around polychaete tubes. Can J Fish Aquat Sci 40:301-308

Daro MH, Polk P (1973) The autecology of Polydora ciliata along the Belgian coast. Neth J Sea Res 6:130-140

Dauer DM, Maybury CA, Ewing RM (1981) Feeding behavior and general ecology of several spionid polychaetes from the Chesapeake Bay. J Exp Mar Biol Ecol 54:21-38

Dorsett DA (1961) The behaviour of Polydora ciliata (Johnst.). Tube-building and burrowing. J Mar Biol Assoc UK 41: $577-590$

Eckman JE, Nowell ARM (1984) Boundary skin friction and sediment transport around an animal-tube mimic. Sedimentology 31:851-862

Eckman JE, Nowell ARM, Jumars PA (1981) Sediment destabilization by animal tubes. J Mar Res 39:361-374

Fauchald K, Jumars PA (1979) The diet of worms: a study of polychaete feeding guilds. Oceanogr Mar Biol Annu Rev $17: 193-284$

Friedrichs M (1997) Report about the characteristics of the NIOO-CEMO flume system - pilot study. NIOO-CEMO, NIOO rapporten 1997-6, Yerseke

Frithsen JB, Doering PH (1986) Active enhancement of particle removal from the water column by tentaculate benthic polychaetes. Ophelia 25:169-182

Gambi MC, Nowell ARM, Jumars PA (1990) Flume observations on flow dynamics in Zostera marina (eelgrass) beds. Mar Ecol Prog Ser 61:159-169

Graf G, Rosenberg R (1997) Bioresuspension and biodeposition: a review. J Mar Syst 11:269-278

Gust G (1989) The benthic boundary layer. In: Hellwege $\mathrm{KH}$, Madelung O (eds) Landoldt-Börnstein, 6th edn. Group V: Vol 3, Subvolume b. Springer, Berlin, p 345-393

Hawley N, Lesht BM (1995) Does local resuspension maintain the benthic nepheloid layer in Southeastern Lake Michigan? J Sediment Res A65:69-76

Hempel C (1957) Über den Röhrenbau und die Nahrungsaufnahme einiger Spioniden (Polychaeta sedentaria) der deutschen Küsten. Helgol Wiss Meeresunters 6:100-135

Jumars PA, Nowell ARM, Self RFL (1981) A simple model of flow-sediment-organism interaction. Mar Geol 42:155-172

Lohrmann A, Cabrera R, Gelfenbaum G, Haines J (1995) Direct measurements of Reynolds stress with an acoustic Doppler velocimeter. In: Anderson PA, Appell GF, Williams AJ (eds) Proceedings of the IEEE 5th Working Conference on Current Measurements, 7-9 Feb 1995. Institute of

Editorial responsibility: Otto Kinne (Editor),

Oldendorf/Luhe, Germany
Electrical and Electronics Engineers, Inc., St. Petersburg, Washington, DC, p 205-210

Luckenbach MW (1986) Sediment stability around animal tubes: the roles of hydrodynamic processes and biotic activity. Limnol Oceanogr 31:779-787

Miller DC, Bock MJ, Turner EJ (1992) Deposit and suspension feeding in oscillatory flows and sediment fluxes. J Mar Res 50:489-520

Muschenheim DK (1987a) The dynamics of near-bed seston flux and suspension-feeding benthos. J Mar Res 45: $473-496$

Muschenheim DK (1987b) The role of hydrodynamic sorting of seston in the nutrition of a benthic suspension feeder, Spio setosa (Polychaeta: Spionidae). Biol Oceanogr 4: 265-288

Noji C, Noji TT (1991) Tube lawns of spionid polychaetes and their significance for recolonization of disturbed benthic substrates. Meeresforschungen 33:235-246

Nowell ARM, Church M (1979) Turbulent flow in a depth-limited boundary layer. J Geophys Res 84:4816-4824

Nowell ARM, Jumars PA (1987) Flumes: theoretical and experimental considerations for simulation of benthic environments. Oceanogr Mar Biol Annu Rev 25:91-112

O'Riordan CA, Monismith SG, Koseff JR (1993) A study of concentration boundary-layer formation over a bed of model bivalves. Limnol Oceanogr 38:1712-1729

Rhoads DC, Yingst JY, Ullmann WJ (1978) Seafloor stability in Central Long Island Sound: Part I. Temporal changes in erodibility of fine-grained sediment. In: Wiley ML (ed) Estuarine interactions. Academic Press, Mount Pocono, PA, p 221-244

Rosenberg R (1976) Benthic faunal dynamics during succession following pollution abatement in a Swedish estuary. Oikos 27:414-427

Rowe GT, Boland GS, Phoel WC, Anderson RF, Biscaye PE (1994) Deep-sea floor respiration as an indication of lateral input of biogenic detritus from continental margins. DeepSea Res II 41:657-668

Shimeta J, Jumars PA (1991) Physical mechanisms and rates of particle capture by suspension-feeders. Oceanogr Mar Biol Annu Rev 29:191-257

Springer B, Friedrichs M, Graf G, Nittikowski J, Queisser W (1999) A high precision current measurement system for laboratory flume systems: a case study around a circular cylinder. Mar Ecol Prog Ser 183:305-310

Stips A, Prandtke H, Neumann T (1998) The structure and dynamics of the Bottom Boundary Layer in shallow sea areas without tidal influence: an experimental approach. Prog Oceanogr 41:383-453

Taghon GL, Nowell ARM, Jumars PA (1980) Induction of suspension feeding in spionid polychaetes by high particulate fluxes. Science 210:562-564

Vogel S (1994) Life in moving fluids. Pergamon, New York

Submitted: January 8, 1999; Accepted: July 5, 1999

Proofs received from author(s): January 21, 2000 